\title{
THE TYPICAL TRAFFIC ACCIDENT IN LITHUANIA IN COMPARISON WITH SWEDEN
}

\author{
RASA UŠPALYTĖ-VITKŪNIENE ${ }^{1 *}$, ALIAKSEI LAURESHYN ${ }^{2}$ \\ ${ }^{1}$ Road Department, Vilnius Gediminas Technical University, \\ Vilnius, Lithuania \\ ${ }^{2}$ Institute of Transport Economics, Lund University, Lund, Sweden
}

Received 17 February 2020; accepted 19 May 2020

\begin{abstract}
Every day we strive to improve the environment and make it as comfortable as possible, creating new products and new technologies that are literally changing people's lives. Transport is one of the most important engines of development in the world and, unfortunately, it is one of the most painful taking into account how many people's lives we are losing in it. Ensuring safe traffic, stabilizing a number of accidents, reducing accidents on motor roads and streets are the most important tasks in the field of transport in Lithuania and the EU today. Lithuania could not be left behind when the EU countries pursued an important goal of halving the number of fatalities by the end of 2010 compared to 2001. Substantial road accident rates are recorded in cities with the highest concentration of road users. The aim of this article is to identify the typical accidents for Lithuanian cities and to compare them with the case of Sweden, which is one of the leading countries in the field of traffic safety. The five largest cities in Lithuania been selected for the analysis, where typical traffic accidents are identified. The analysis will help develop recommendations for changes in traffic infrastructure to ensure safe traffic.
\end{abstract}

Keywords: pedestrians' safety, traffic safety, typical accident.

* Corresponding author. E-mail: rasa.uspalyte@vgtu.lt

Rasa UŠPALYTĖ-VITKŪNIENĖ (ORCID ID 0000-0002-8742-5065)

Aliaksei LAURESHYN (ORCID ID 0000-0002-1117-6496)

Copyright (C) 2020 The Author(s). Published by RTU Press

This is an Open Access article distributed under the terms of the Creative Commons Attribution License (http://creativecommons.org/licenses/by/4.0/), which permits unrestricted use,

distribution, and reproduction in any medium, provided the original author and source are credited. 


\section{Introduction}

Lithuania was and still is one of the worst countries in the European Union in terms of traffic accident indicators. However, with every effort it reduces the accident rate and its consequences in the country to boast of a higher position every year. Ensuring traffic safety, stabilising accident rate, reducing the number of killed and injured persons on roads and streets are the most important tasks in the field of transport not only in Lithuania, but also in the EU. The development of a common EU road safety management system policy is based on the development of guiding principles for road safety. The system consists of several elements (Durant \& Legge, 1993; Kristianssen, Andersson, Belin, \& Nilsen, 2018; Yannis, Thomas, Papadimitriou, Talbot, \& Martensen, 2016):

- philosophy of action. The key message is that improving road safety has to be based on an effective, science-based action that will reduce the number of road accidents and their victims, under the condition that they be perceived as a problem for society as a whole;

- databases. Anyone who declares their readiness to improve road safety is invited to take preventive action. At the same time, databases have to be made universally accessible. In addition, scientific solution to the problem requires accurate data on the circumstances, the course and the consequences of the event, and the socio-economic costs;

- scientific basis for action. A road accident consists of many components, so there can be no question of its elimination as a test method. All decisions have to be based on scientific knowledge;

- a clear and logical action programme has to provide clear quantifiable indicators over time, such as reducing road deaths by $20 \%$ over a 5-year period;

- distribution of responsibilities between the programme main representative and coordination at the appropriate level: country, region and local;

- monitoring. The effectiveness of the actions has to be evaluated by an independent research centre in order to adjust the programme during its execution;

- a system to measure effectiveness. The implementation of the selected measures to improve road safety requires detailed research and an evaluation of the effectiveness of implementation.

Since the launch of a common policy on the road safety management system in the EU, new ambitions have been constantly set and
The Typical Traffic Accident in Lithuania in Comparison With Sweden 
ever-higher goals have been formulated in the area of road safety. The EU signed the Maastricht Treaty in 1992. Preventive action has been considered to improve road safety. The European Commission was set up to improve road safety and to ensure greater effectiveness than the impact of individual actions in separated countries. At the end of the last century, when the number of casualties exceeded 45000 every year, a programme was set up that included qualitative road safety goals: "Reduce fatalities by $40 \%$ by 2010 ". Another document "White paper - European transport policy for 2010: Time to decide" was issued in November 2001. This programme has set the new quantitative target that is the reduction in the number of road accidents by half or to no more than 20 thousand casualties in 2010. In addition to the quantitative objective, two additional objectives have been formulated: "Reduce the severity of accidents" and "Improve assistance to accident victims".

The Transport Ministers of the European Union countries pledged to reduce the number of fatalities by $50 \%$ between 2001 and 2010 in 2000. To achieve this goal, methodical decision-making had to be approached. The European Road Safety Action Programme has identified a number of key areas for action: encouraging road users to be more responsible, ensuring greater vehicle safety through technical progress and improving road infrastructure through the use of information and communication technologies. Successive EU countries have enshrined these commitments at the national level. The emphasis that special effort should be made in those cases where road safety is below the European Union average, supported by close cooperation and knowledge exchange among the Member States, was put in the Valletta Declaration accepted in 2017 (EU Commission, n. d.) (Figure 1).

However, despite the fact that accident rates in the country are improving, the number of fatalities on Lithuanian roads has decreased

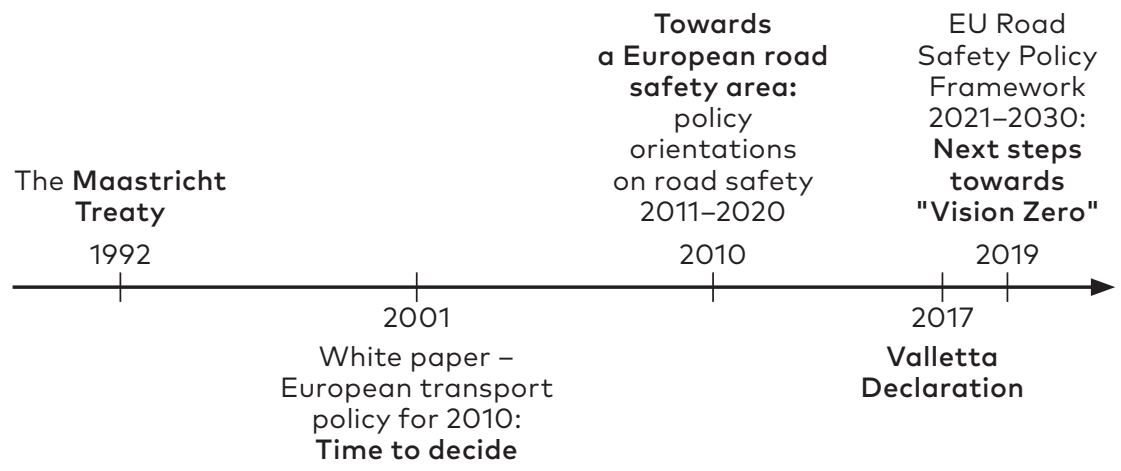

Figure 1. Chronology of the EU acts for road safety 
by 36 per cent over the past seven years (Figure 2). Lithuania remains among the countries with the biggest road death rate in the European Union. In accordance with the data provided by Lithuania in 2017, it ranked only 22nd out of 28 European Union countries (EU Commission, 2018).

The Scandinavian scientist Elvik (1995) investigated the economic valuation of a fatality traffic accident type and analysed the costs of a traffic accident fatality in various countries by a traffic accident type. Russo, Biancardo, \& Dell'Acqua (2014), George, Athanasios, \& George (2017) and Ab Malek, Salim, Alias, Zaki, \& Ab Malek (2019) analysed the risk for fatal injury in a road traffic accident using logistic regression adjusting for gender, age, time of the day of an accident, vehicle types and accident cases. Among the variables obtained, two independent variables were found significantly associated with fatal accidents; namely, vehicle types (lorry/truck and others) and accident cases (over speed and sudden change signal) (Ab Malek et al., 2019). Therefore, it can be concluded that crash type plays an important role when accident severity is examined. This is also shown in a previous study by Theofilatos, Graham, \& Yannis (2012). Thanks to the proposed measures of risk for classifying sections of streets, those sections could be identified that are most likely to achieve an accident reduction (especially those involving seriously injured persons and fatalities) and

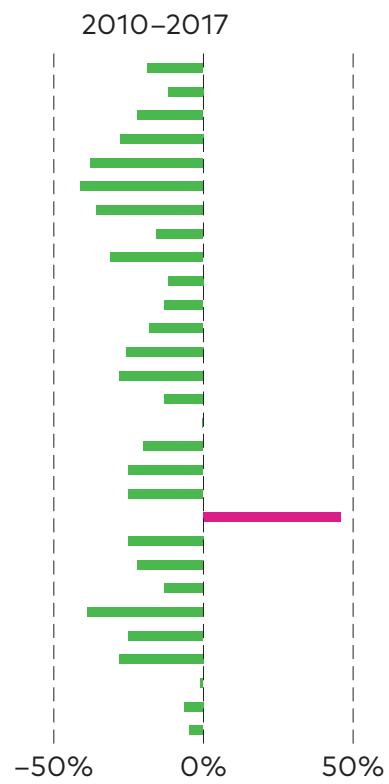

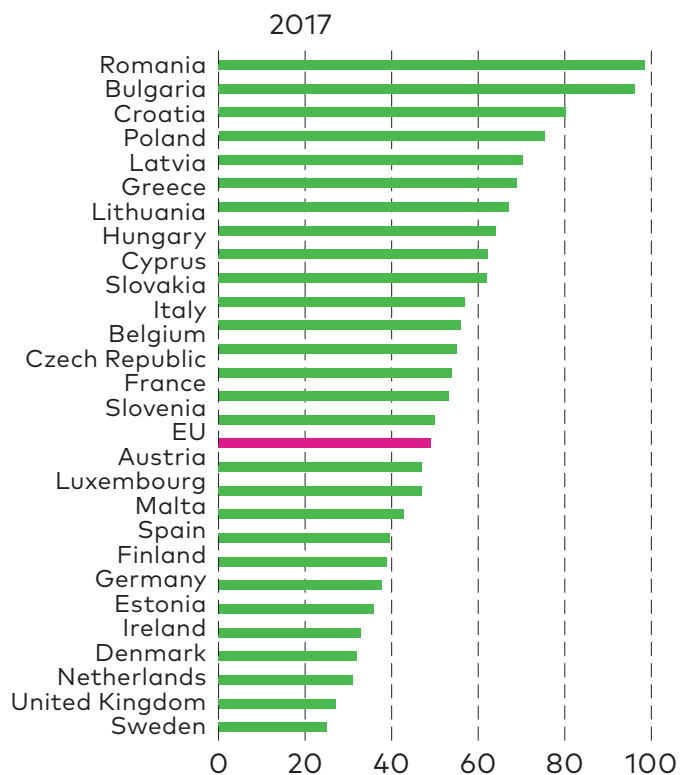

Figure 2. Road deaths per million inhabitants in 2017 and changes from 2010 
those that are likely to be economically effective in the case of specific treatments.

The models proposed by Wachnicka, Budzyński, Kustra, \& Gobis (2019) could be used to estimate the effects of selected factors on road safety and, as a consequence, to take the most effective road safety measures. With new analyses and research, it will be possible to extend the models and use them as tools for road safety management.

The findings of scientists show meaningful interpretations that can be used for future traffic safety improvement.

Cities are the major contributors to traffic accidents, and solutions for urban transport systems should be the priority. During the past decade, Lithuania has invested a lot in road safety, but the improvement of the situation is not very significant. Identifying typical traffic accidents in cities could provide targeted funding for major road safety problems. The aim of this article is to identify the typical accidents in Lithuanian cities and to compare them with the case of Sweden, which is one of the leading countries in the field of traffic safety. The five largest cities in Lithuania have been selected for the analysis, where typical traffic accidents are identified. It will help develop recommendations for changes in traffic infrastructure ensuring safe traffic.

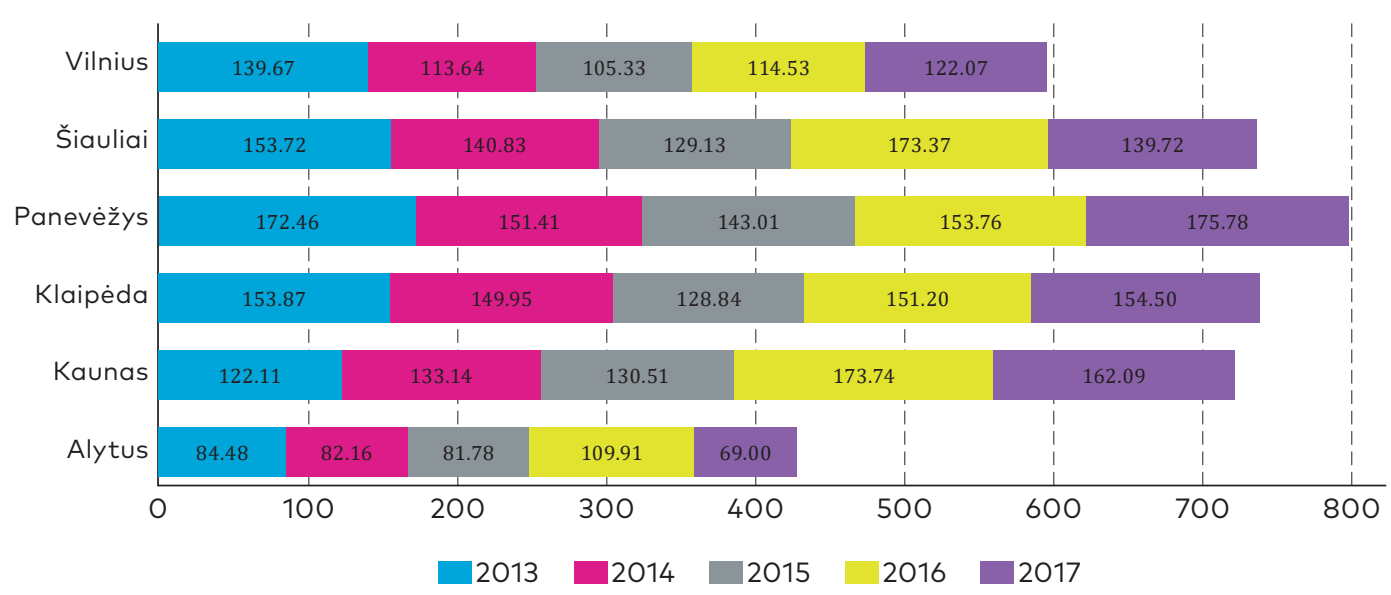

Figure 3. The number of recorded traffic injury accidents per 100 thousand inhabitants in the largest cities of Lithuania (Lithuanian Road Administration, n. d.) 


\section{General problem in Lithuanian cities}

The Typical Traffic Accident in Lithuania in Comparison With

More than 3000 injury accidents are recorded in Lithuania every year. According to the data of the Lithuanian Road Police Service, one hundred and ninety-two people were killed and three thousand seven hundred and fifty-two were injured on Lithuanian roads and streets in 2017. In regard with the statistics presented in Figure 3, we can see the general statistics of traffic accidents in the largest cities of Lithuania in proportion to the population. Panevėžys, Šiauliai, Kaunas and Klaipèda are the leading cities in the field of traffic accidents. Therefore, traffic accident statistics of Panevėžys, Kaunas and Klaipėda have been selected for further investigation.
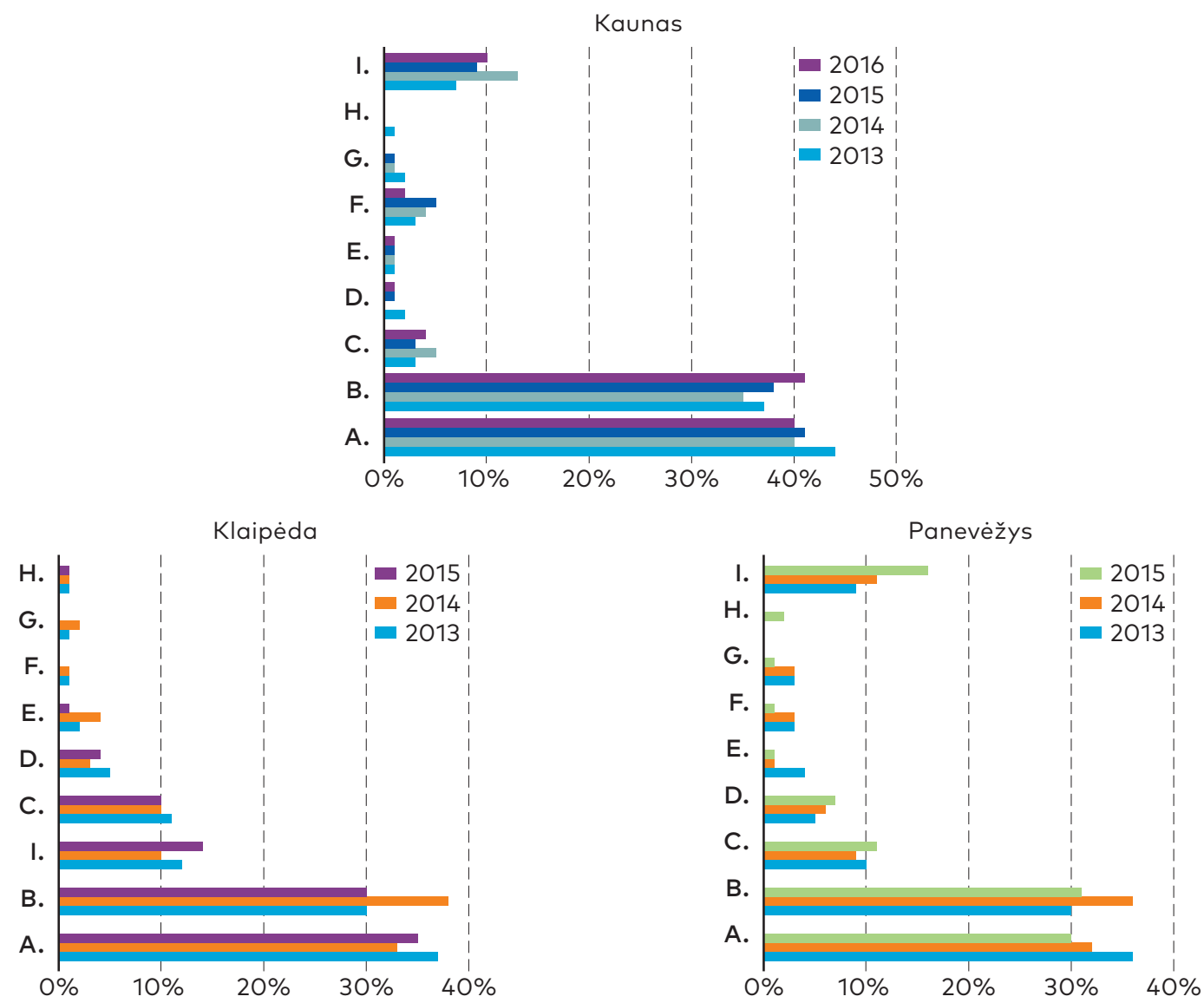

Figure 4. Statistics of traffic accidents by type. A - Motor $V$ vs pedestrian; B - Motor V vs Motor V, C - Motor V vs bicycle, D - Rollover; E - Motor V vs standing Motor $\mathrm{V}, \mathrm{F}$ - Driveway and obstacle; $\mathrm{G}$ - Motor $\mathrm{V}$ vs motorcycle; $\mathrm{H}$ Motor V vs motorbike; I - Other 
Some authors, e.g., Feldstain, Dietrich, Milinkovic, \& Bengler (2016) affirm that the pedestrians are not the most vulnerable users, but from the analysis of the main cities in Lithuania a different situation is visible. The largest share of traffic accidents in all major cities is pedestrian access, which accounts for $33-44 \%$ of all traffic accidents in the city (Figure 4), indicating that this problem is very significant in Lithuanian cities and it needs to be addressed immediately. Collisions between two cars account for a similar proportion and range from 30\% to 38\% in annual statistics on urban accidents.

\section{Typical accident. Pedestrian collisions}

A closer insight reveals that half of the accidents occur when a pedestrian crosses a pedestrian crossing (Figure 5). The proportion of pedestrians crossing in pedestrian crossings ranges from $34-41 \%$ in Panevėžys to $65-69 \%$ in Kaunas, out of the total number of pedestrian crossings. This demonstrates both negligence of pedestrians and intolerance of driver as well as disrespect for pedestrians and carelessness about their lives. Therefore, this shows the special point in the city transport systems with a simple solution addressing this problem that is better infrastructure on pedestrian crossings, which could save human lives.
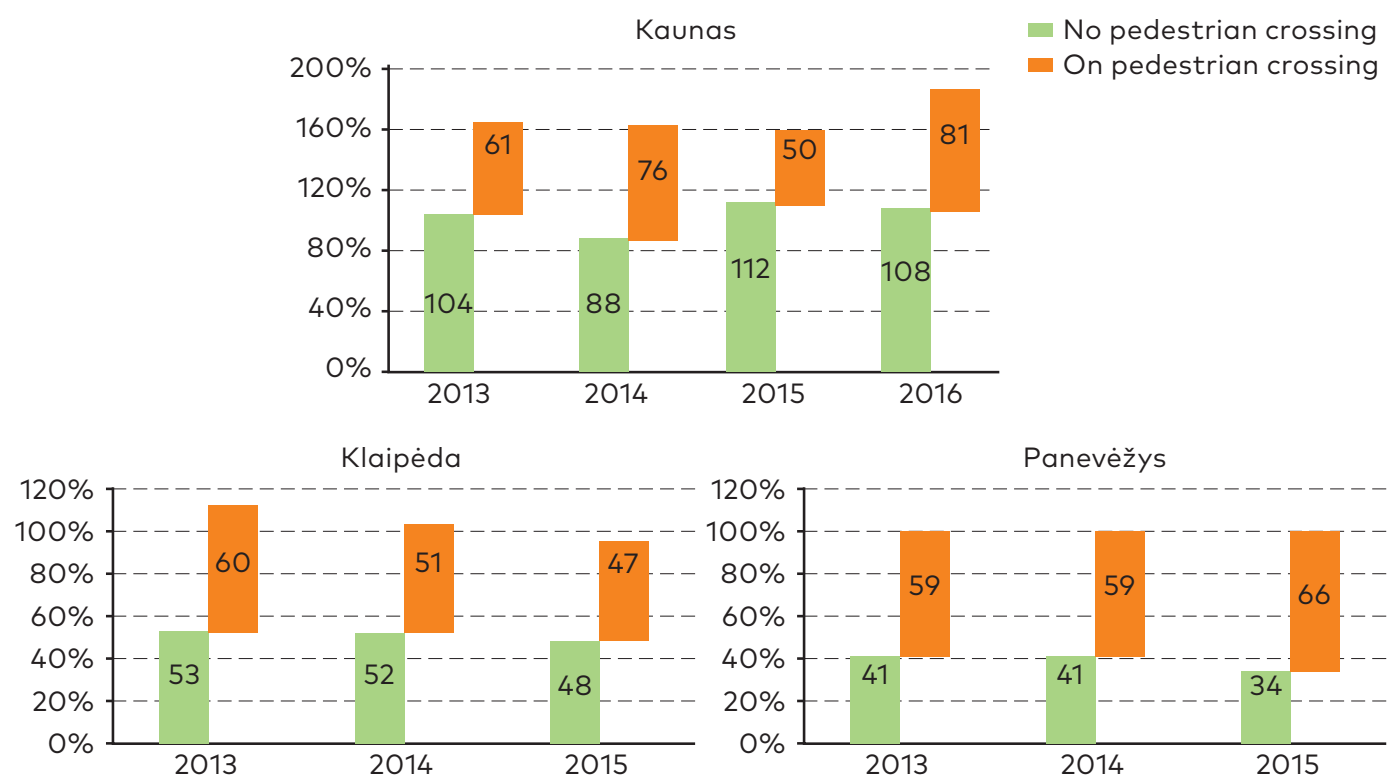

Figure 5. Pedestrian collisions in three largest Lithuanian cities 
For further analysis of accidents involving pedestrians on the crossing, the time of the day when the driver had good visibility and when visibility was poor should be distinguished. All the cities received the same trend. According to the data, the percentage, for example, road traffic accidents with pedestrian traffic in Kaunas are almost evenly distributed during the day or during the dark or twilight (Figure 6). On a day when pedestrians see each other well, it is harder to adjust. However, accidents that clearly lacked visibility could be easily solved by installing bright directional lighting in pedestrian crossings to allow pedestrians to see distantly.

The main pedestrian street crossing problem was simulated by scientists, e.g., Feldstain et al. (2016), Su, Chen, Wang, Chen, \& Wang (2017), Subramanian et al. (2018) and Woodman et al. (2019). They suggested that ground markings could be used to add a visual separation between pedestrian and motor vehicles. This finding has potential policy implications for urban design as the layout of pedestrianised areas will need to provide enough space for vehicles to operate. The speed limitation before the pedestrian crossing was suggested as well like one of the good safety measures. Moreover, lightening was the third main measure suggested for the safety on the pedestrian crossings. Subramanian et al. (2018) have done two experiments examining pedestrian road crossing in conditions of night lighting using an immersive pedestrian simulator. In the first experiment, participants crossed a traffic-filled roadway in either day or night-time lighting conditions. The obtained results showed that gap selection and movement timing were similar in the conditions of day and night-time. In the second experiment, participants were standing on the edge of a virtual road in night-time conditions and making judgements of the last safe moment to cross before an approaching vehicle reached the participant.

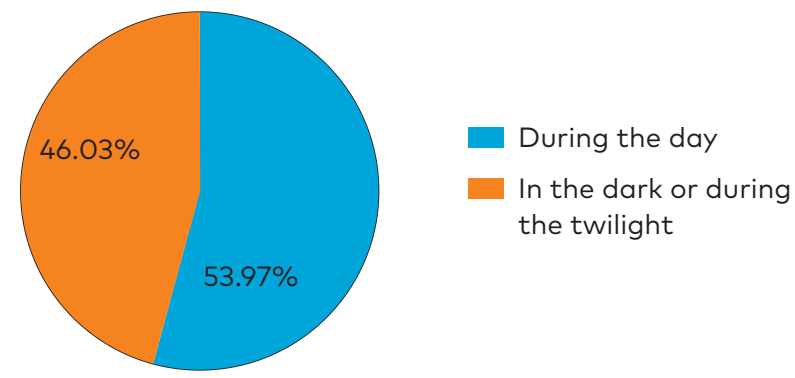

Figure 6. Pedestrian collisions in three largest Lithuanian cities
The Typical Traffic Accident in Lithuania in Comparison With Sweden 


\section{Typical accident. Collision of two motor vehicles}

For collisions between two motor vehicles (Figure 7), collisions moving in the same direction are most pronounced. They account for $44-53 \%$ of all collisions. These most illogical road accidents could not happen if road users obeyed the rules of the road and were at least more careful.

A closer insight into the circumstances of collisions in the same direction reveals that most of them (58-67\%) occur due to one vehicle driving into the rear of another vehicle. These circumstances occur when vehicles do not keep speed limits and safe distance. To prevent such accidents, there is a need to implement traffic safety measures to encourage drivers to keep to a safe speed, which is a roller coaster and it should be installed on lower category streets (D-C2 category streets). Higher-speed streets should be fitted with speed meters (A1-A2 category streets).

\section{Comparison between the Lithuanian and Swedish accident patterns}

Sweden is one of the best-performing countries when it comes to traffic safety. It had 25 persons killed in traffic per 100000 people in 2017, while in Lithuania the number was 67. In further analysis, the detailed data from two major Swedish cities, Gothenburg and Malmö, which are comparable in size and population of the selected Lithuanian cities, was used.

Figure 8 shows the distribution of accidents by the type of involved road users according to the official statistics (based on police data only). The classification categories are not completely compatible with the categories used in Figure 4; however, the most frequent accident types can be directly compared.

Like in Lithuania, injuries appear to come to a high degree from collisions between motor vehicles or at least with motor vehicles involved. Unlike in Lithuania, where collisions with pedestrians are very common, they stand for only $12-15 \%$ of the total injury accidents in the Swedish cities. The difference in the share of collisions with bicycles between Malmö and Gothenburg is explained primarily by the difference in exposure, i.e., the number of cycling trips being made. Malmö is smaller in size geographically, it has a flatter terrain and milder winters which all together contribute to bicycling as a transport means.

The process of recording accident information on site should be automated to reduce human errors and the loss of information during 
transfer from manual reports to a digital database. The Swedish accident database STRADA (n. d.) includes both police reports and hospital injury records that have been identified as traffic-related. Even though the official statistics is still based on police records only, the analysis of the hospital data provides valuable insights into the scale of under-reporting as well as its distribution among the accident categories. Awareness of reporting accidents to the police, particularly those which involve a
The Typical Traffic Accident in Lithuania in Comparison With Sweden
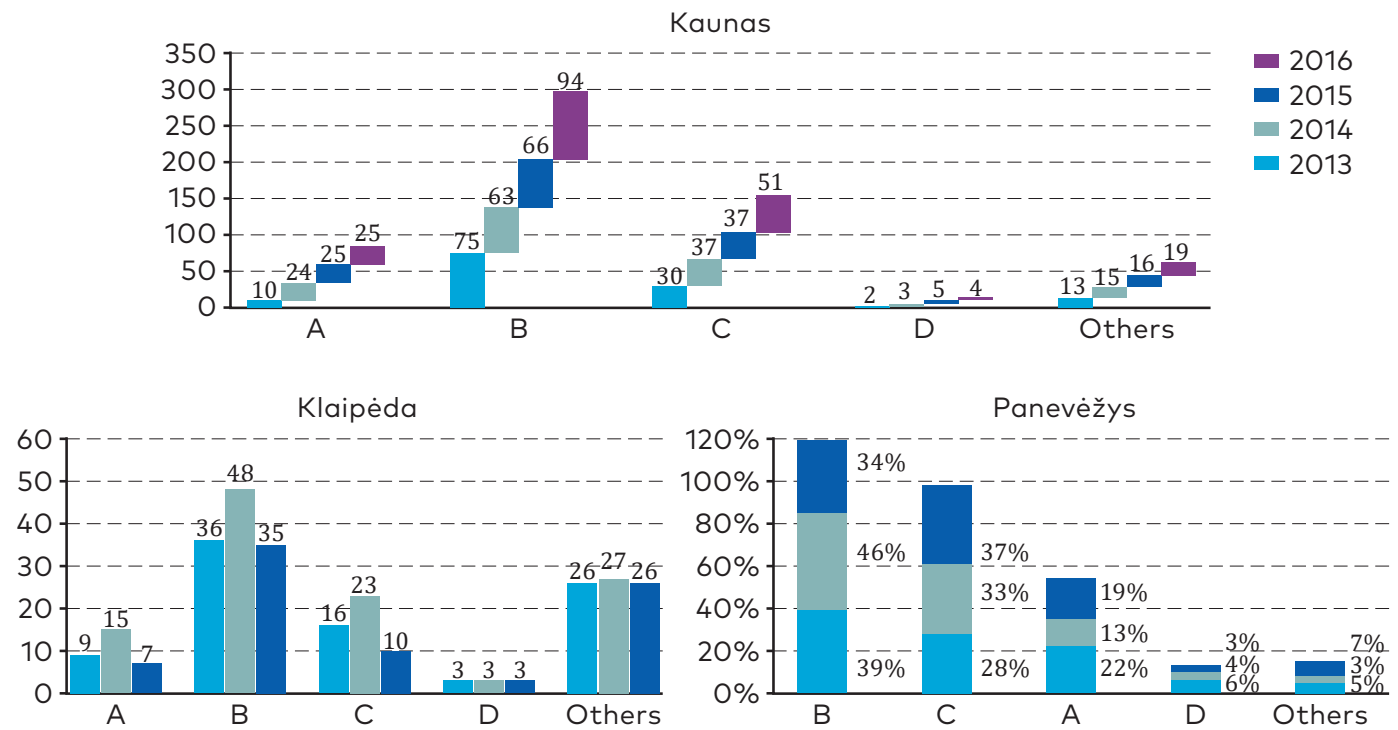

Figure 7. Type of collisions between two motor vehicles in the Lithuanian cities Kaunas, Klaipeda and Panevėžys. A - Counter-collisions; B - Collisions moving in the same direction; C - Left-hand collisions (turns); D - Right-hand collisions
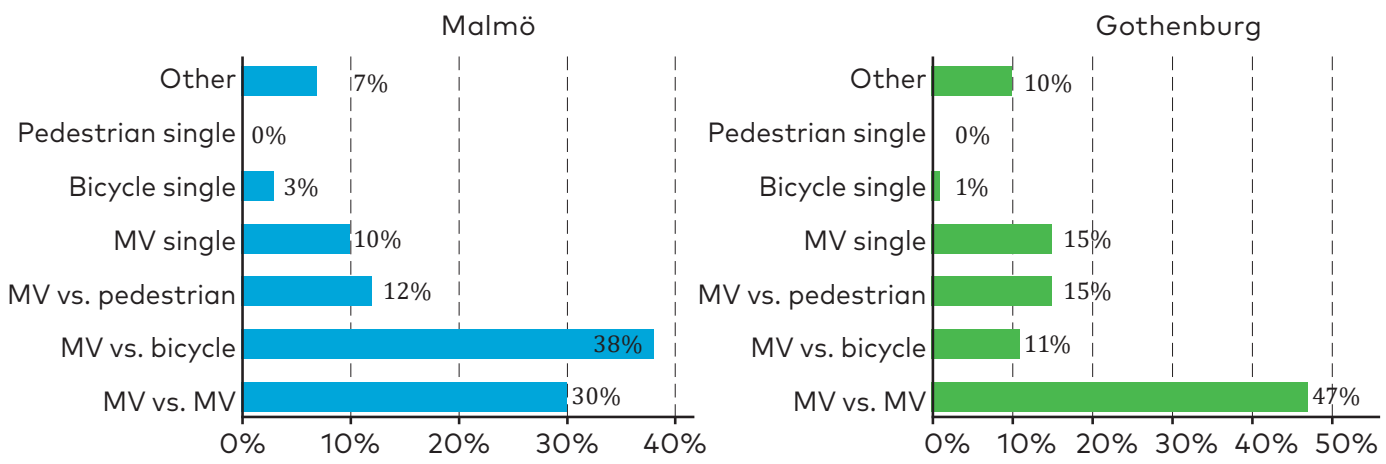

Figure 8. Distribution of personal injury accidents by involved road users in Gothenburg and Malmö, 2017 (official statistics based on police data). MV stands for 'Motor Vehicle' 
single vehicle, pedestrian or bicyclist, and slight or no injury, should to be stressed. Such accidents in most of the countries are not recorded at all. Ahmed, Sadullah, \& Yahya (2019) found out that in high-income countries the extent of error in reporting slight, severe, non-fatal and fatal injury accidents varied between $39-82 \%, 16-52 \%, 12-84 \%$, and $0-31 \%$, respectively. For middle-income countries, the error for the same categories varied between $93-98 \%, 32.5-96 \%, 34-99 \%$ and $0.5-89.5 \%$, respectively. The only four studies available for low-income countries showed that the error in reporting non-fatal and fatal accidents varied between $69-80 \%$ and $0-61 \%$, respectively.

Inclusion of the personal injury reports from hospitals changes the picture dramatically. First of all, it becomes apparent that a significant number of traffic injuries is not known to the police; thus, the scale of the road safety problem is under-estimated generally. Moreover, underreporting hits the different road user categories unequally. Particularly vulnerable road users (VRUs) suffer, and in case of single accidents (both for pedestrians and cyclists) practically all data come from the hospitals only. It can also be obvious that VRU single accidents are the leading causes of the personal injuries.

\section{Conclusions}

The most typical accidents in the Lithuanian cities are:

- pedestrian access in both cases (at the crossing and when there is no crossing), which accounts for $35 \%$ in all analysed Lithuanian cities;

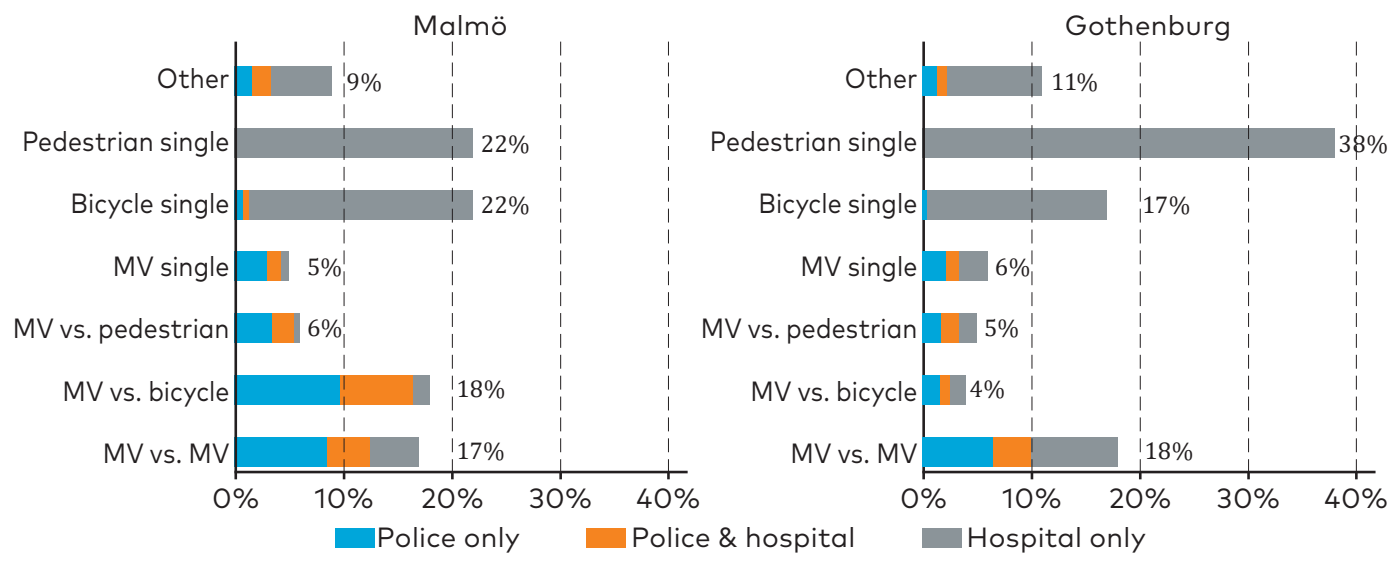

Figure 9. Personal injury accidents in Gothenburg and Malmö, 2017 (police and hospital data included) 
- collision of a motor vehicle on the back of another motor vehicle due to non-compliance with safe speed and distance $\approx 10 \%$.

Comparison of the Lithuanian accident data with official data from the Swedish cities does not reveal any particular differences or surprises. However, the distribution of accidents in the STRADA dataset that includes the hospital records is fundamentally different. Hospital records of data reveal that there is a significant number of traffic injuries not known to police, and that the leading causes of injuries are different.

The studies using hospital data on traffic injuries have never been performed in Lithuania. However, they have been performed in other countries than Sweden (the Netherlands, Denmark, France, etc.) and demonstrated very similar results. Therefore, there are no grounds to believe that the situation in Lithuania is particularly different, but the absence of the relevant data does not allow drawing attention to the 'actual' problems of urban traffic. For that reason, it is ultimately urgent to perform a study on under-reporting based on Lithuanian data sources that could be accepted by the public, authorities and politicians.

Investing in the transport infrastructure to prevent or mitigate the consequences of these two types of accidents in Lithuania specifically would result in faster results in terms of road safety. However, comparing the statistical data with the case of Sweden shows that the new uncovered problem of non-recorded traffic accidents with pedestrians, who could do this type of accident, is even more significant. There is still a practice that only the police in Lithuania record traffic accidents. Currently, statistics from the hospitals on the number of people injured in traffic accidents are not yet included into official statistics.

It is the priority in many European cities (including Lithuania) to promote 'green' means of transport (including walking), and if so, their safety has also been considered. The means of countering the single accidents are to a high degree in hands of traffic engineers, e.g., maintenance of the sidewalks, removal of snow and gravel, de-icing, etc.

\section{REFERENCES}

Ab Malek, I., Salim, N. N. M., Alias, S. N., Zaki, N. A. M., \& Ab Malek, H. (2019). Road Fatalities Using Logistic Regression. In Proceedings of the Third International Conference on Computing, Mathematics and Statistics (iCMS2017) (pp. 405-411). Singapore: Springer. https://doi.org/10.1007/978-981-137279-7_50

Ahmed, A., Sadullah, A. F. M., \& Yahya, A. S. (2019). Errors in Accident Data, Its Types, Causes and Methods of Rectification-Analysis of the Literature. 
Accident Analysis \& Prevention, 130, 3-21. https://doi.org/10.1016/j. aap.2017.07.018

Durant, R. F., \& Legge, J. S. (1993). Policy Design, Social Regulation, and Theory Building: Lessons From the Traffic Safety Policy Arena. Political Research Quarterly, 46(3), 641-656. https://doi.org/10.1177/106591299304600310

Elvik, R. (1995). An Analysis of Official Economic Valuations of Traffic Accident Fatalities in 20 Motorized Countries. Accident analysis \& prevention, 27(2), 237-247. https://doi.org/10.1016/0001-4575(94)00060-Y

EU Commision. (2018). Road Safety: Data Show Improvements in 2017 but Renewed Efforts Are Needed for Further Substantial Progress. Retrieved from https://ec.europa.eu/commission/presscorner/detail/en/IP_18_2761 [Accessed on 10 December 2019].

EU Commission. (n. d.). Mobility and Transport. Road Safety. Retrieved from https://ec.europa.eu/transport/road_safety/home_en [Accessed on 15 December 2019].

Feldstein, I., Dietrich, A., Milinkovic, S., \& Bengler, K. (2016). A Pedestrian Simulator for Urban Crossing Scenarios. FAC-PapersOnLine, 49(19), 239-244. https://doi.org/10.1016/j.ifacol.2016.10.531

George, Y., Athanasios, T., \& George, P. (2017). Investigation of Road Accident Severity per Vehicle Type. Transportation research procedia, 25, 2076-2083. https://doi.org/10.1016/j.trpro.2017.05.401

Kristianssen, A. C., Andersson, R., Belin, M. Å., \& Nilsen, P. (2018). Swedish Vision Zero policies for Safety - A Comparative Policy Content Analysis. Safety science, 103, 260-269. https://doi.org/10.1016/j.ssci.2017.11.005

Lithuanian Road administration. (n. d.). Traffic accident statistic. Retrieved from http://lakd.lrv.lt/ [Accessed on 20 March 2019]. [In Lithuanian].

Russo, F., Biancardo, S. A., \& Dell'Acqua, G. (2014). Consistent Approach to Predictive Modeling and Countermeasure Determination by Crash Type for Low-Volume Roads. Baltic Journal of Road \& Bridge Engineering, 9(2), 77-87. https://doi.org/10.3846/bjrbe.2014.10

STRADA - Swedish Traffic Accident Data Acquisition'. (n. d.). Retrieved from https://www.transportstyrelsen.se/STRADA [Accessed on 20 March 2019]. [In Swedish].

Su, J., Chen, J., Wang, H., Chen, W., \& Wang, K. (2017). Establishment and Analysis on Typical Road Traffic Near-Crash Scenarios Related to Pedestrian in China. Traffic and Transportation, 209-214.

Subramanian, L. D., O’Neal, E. E., Mallaro, S., Williams, B., Sherony, R., Plumert, J. M., \& Kearney, J. K. (2018). Pedestrian Road Crossing in Nighttime Lighting Conditions Using an Immersive Simulator (No. 18-01218). In Transportation Research Board 97th Annual Meeting.

Theofilatos, A., Graham, D., \& Yannis, G. (2012). Factors Affecting Accident Severity Inside and Outside Urban Areas in Greece. Traffic injury prevention, 13(5), 458-467. https://doi.org/10.1080/15389588.2012.661110

Wachnicka, J., Budzyński, M., Kustra, W., \& Gobis, A. (2019). The Effects of Selected Factors on Regional Road Fatalities - Analysis of the Łódź Region. In MATEC Web of Conferences (vol. 262, pp. 5-16). EDP Sciences. https://doi. org/10.1051/matecconf/201926205016 
Woodman, R., Lu, K., Higgins, M. D., Brewerton, S., Jennings, P. A., \& Birrell, S. (2019). Gap Acceptance Study of Pedestrians Crossing Between Platooning Autonomous Vehicles in a Virtual Environment. Transportation research part F: traffic psychology and behaviour, 67, 1-14. https://doi.org/10.1016/j. trf.2019.09.017

Yannis, G., Thomas, P., Papadimitriou, E., Talbot, R., \& Martensen, H. (2016). 80 Developing the European Road Safety Decision Support System. Injury Prevention, 22(Suppl 2), A30.3-A31. https://doi.org/10.1136/injuryprev2016-042156.80

\section{NOTATIONS}

\section{Abbreviations}

EU - European Union;

VRU - Vulnerable Road Users.
The Typical Traffic Accident in Lithuania in Comparison With Sweden 